in vivo $34: 2431-2435(2020)$

doi:10.21873/invivo.12057

\title{
Evaluation of Renal Function in Obstructed Ureter Model Using 99mTc-DMSA
}

\author{
SEOK JIN JANG ${ }^{1}$, BYUNG SOO CHOI ${ }^{2}$ and SEOK HWA CHOI ${ }^{2}$ \\ ${ }^{1}$ Onnuri Animal Medical Center, Cheongju, Republic of Korea; \\ ${ }^{2}$ College of Veterinary Medicine, Chungbuk National University, Cheongju, Republic of Korea
}

\begin{abstract}
Background/Aim: Urinary obstruction is a condition of impaired urinary drainage, which may result in progressive renal deterioration. This study applied ${ }^{99 m} T c$ labeled dimercaptosuccinic acid $\left({ }^{99 m} T c-D M S A\right)$ renal scintigraphy to a rabbit model of right ureter obstruction and evaluated its utility in studying obstructive renal diseases. Materials and Methods: Complete unilateral ureter obstruction in rabbits was generated by complete ligation of the right ureter. Renal function was investigated during a 4-week postobstruction period by obtaining planar images of ${ }^{99 m} T c-D M S A$ activity following ear vein injection. Renal blood perfusion was evaluated by non-invasive scintigraphy in conjunction with parallel histological and hematological examinations. Results: Renal perfusion was remarkably and rapidly reduced in the ureter-obstructed kidneys. During the experimental period, the size of left kidney appeared normal in the scintigraphic images, but the ureter-obstructed right kidney progressively became larger. Histopathological examination showed flattening and atrophy of tubules, enlargement of interstitial areas, accumulation of extracellular martices and infiltration of inflammatory cells in the obstreucted kidney. Conclusion: ${ }^{99 m}$ Tc-DMSA scintigraphy is a sensitive, non-invasive method to assess renal function in unilateral kidney diseases.
\end{abstract}

Ureters are fibromuscular ducts that carry urine from the kidney to the urinary bladder. Movement of urine occurs by peristaltic activity, which is transmitted from one muscle cell to the next. Urinary obstruction is a common clinical problem and a frequent cause of renal impairment (1). Renal dysfunction can involve progressive structural changes that

This article is freely accessible online.

Correspondence to: Seok Hwa Choi, DVM, Ph.D., College of Veterinary Medicine, Chungbuk National University, 1 Chungdae-ro, Seowon-gu, Cheongju, Chungbuk, 28644, Republic of Korea. Tel: +82 432613144, Fax: +82 432613224, e-mail: shchoi@cbnu.ac.kr

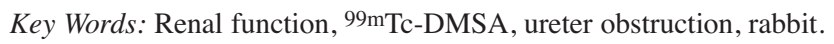

can occur in a variety of glomerular disorders, including pyelonephritis, urinary tract obstruction, and renal malfunction. Renal function can be estimated by performing renal scintigraphy using various radionuclides, such as ${ }^{99 \mathrm{~m}} \mathrm{Tc}-$ labeled dimercaptosuccinic acid ( $\left.{ }^{99 \mathrm{~m}} \mathrm{Tc}-\mathrm{DMSA}\right),{ }^{99 \mathrm{~m}} \mathrm{Tc}-$ labeled mercaptoacetyltriglycine ( $\left.{ }^{99 \mathrm{~m}} \mathrm{Tc}-\mathrm{MAG} 3\right)$, and ${ }^{99 \mathrm{~m}} \mathrm{Tc}-$ labeled diethylenetriaminepentaacetate ( $\left.{ }^{99 \mathrm{~m}} \mathrm{Tc}-\mathrm{DTPA}\right)(2)$. Other non-invasive modalities and procedures for determining renal function include computed tomography (CT)-based angiography (3), dynamic contrast magnetic resonance (MR) urography (4), and diffusion-weight MR imaging (5). When assessing renal disease, it is important to consider various functional parameters, which reflect the administered radiopharmaceutical and the underlying disease status (1). Kidney scans are often performed to determine differential renal functioning in patients undergoing urological surgery (4).

Kidney scintigraphy involves the use of a radiological technique referred to as nuclear medicine. Nuclear medicine is a type of diagnostic radiology that can provide detailed physiological information on disease processes. The nuclear medicine technique usually involves the administration of radionuclides attached to drugs that move to specific organs within the body. The administered radionuclides emit gamma rays, that can be imaged using a specialized gamma camera. Organ functioning can be determined by assessing the positions and relative amounts of the radionuclides within the organ of interest. In renal scintigraphy, the amount of radionuclides extracted from the blood by the kidney is proportional to the level of renal function and is calculated as the glomerular filtration rate (GFR). Other imaging techniques such as diagnostic radiology and ultrasound are useful in determining the structural or anatomic details of the kidney, but neither technique measures renal function.

Quantitative renal scintigraphy is distinct as it allows rapid, non-invasive measurement of renal function in awake animals. The quantitative renal scintigraphy protocol requires the patient to lie down for less than $10 \mathrm{~min}$. Once the radionuclide is injected, images of the kidneys are acquired with a gamma camera and stored on a nuclear medicine computer for later analysis. The computer can determine the GFR of each kidney 


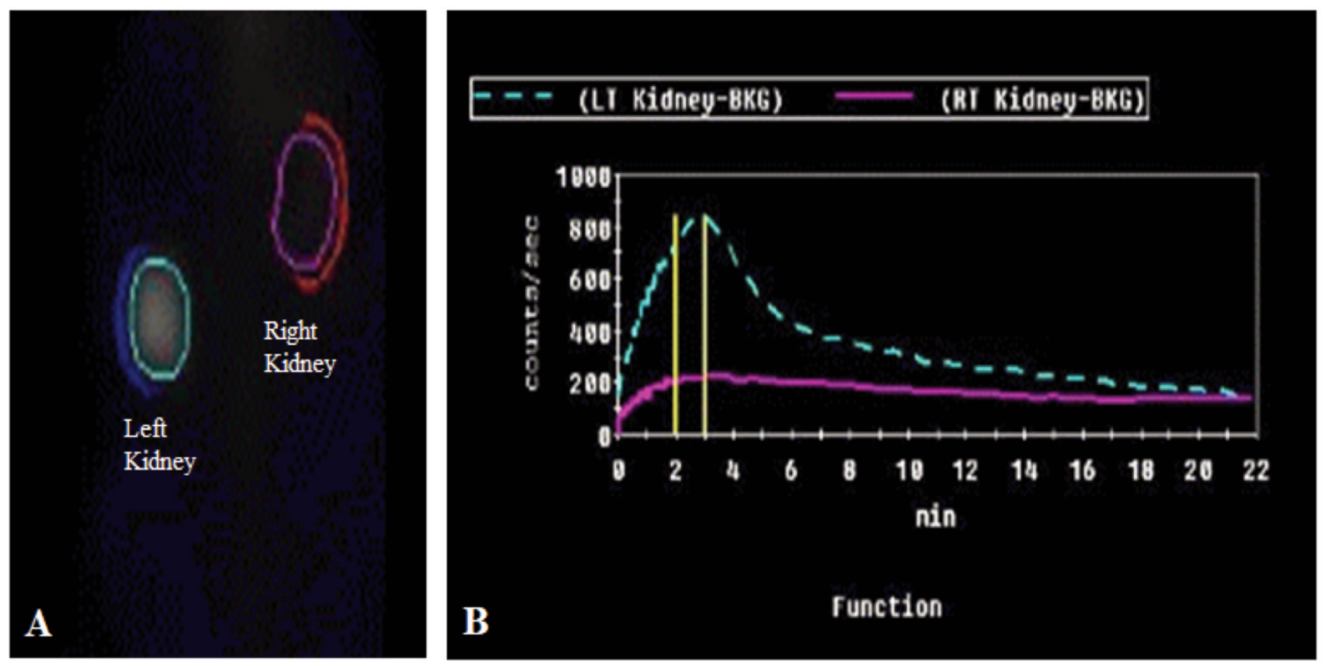

Figure 1. Renal scintigraphy results in a rabbit model with right ureter obstruction after bolus injection of 99mTc-DMSA. (A) A posteroanterior view shows regions of interest drawn for both kidneys. (B) Time-radioactivity curves for left (green curve, dotted line) and right (red curve) kidneys.

by measuring the amount of radionuclide taken up by the individual kidney (1). Kidney scintigraphy has been widely used in human medicine for decades and is now a useful clinical tool for assessing renal function in animals. Kidney disease is one of the most common illnesses affecting veterinary patients. Many conditions can affect the kidney, including infection, neoplasia, cysts, kidney stones, toxin exposure, and various inflammatory diseases. Successful management of these diseases depends, in part, on the ability to assess changes in the extent of the disease or condition after treatment. Blood and urine tests can measure overall kidney function but are not able to measure individual kidney function. In some cases, the ability to measure individual renal function is critical, as such cases can include an expectation of nephrotomy or nephrectomy. Under normal conditions, animals have sufficient renal function to survive with only one functioning kidney. Unfortunately, this does not necessarily apply to individuals with renal diseases. Knowledge of the level of function of the individual kidneys can have a significant effect on plans to surgically remove kidney stones or an entire kidney damaged by an infection or tumor. In such cases, quantitative renal scintigraphy can assess the level of renal function that may persist after such surgical procedures. Quantitative renal scintigraphy does not require sedation or general anesthesia and can be performed on an outpatient basis.

Use of ${ }^{99 m}$ Tc-labeled compounds, such as ${ }^{99 m} \mathrm{Tc}^{-M_{A G}}$, ${ }^{99 \mathrm{~m}} \mathrm{Tc}-\mathrm{DTPA}$, and ${ }^{99 \mathrm{~m}} \mathrm{Tc}-\mathrm{DMSA}$, has made kidney scintigraphy a useful nuclear medicine assessment method (7). Of these, ${ }^{99 \mathrm{~m}} \mathrm{Tc}-\mathrm{DMSA}$ is considered to be the most reliable when measuring renal function (8). However, ${ }^{99} \mathrm{~m}$ Tc-DMSA has disadvantages, such as relatively high radiation dose and time consumption compared to those of ${ }^{99 \mathrm{~m}} \mathrm{Tc}-\mathrm{DTPA}$ or
${ }^{99} \mathrm{~m}_{\mathrm{Tc}}-\mathrm{MAG}_{3}$. Renal scintigraphy with ${ }^{99 m} \mathrm{Tc}-\mathrm{DMSA}$ is widely used to evaluate renal function in humans; however, its use in animal models of renal disease is currently limited.

In this study, we evaluated the usefulness of applying ${ }^{99} \mathrm{~m}$ Tc-DMSA renal scintigraphy to a rabbit model of obstructive renal disease. The animal underwent complete ureter obstruction. The purpose of this study was to assess non-invasive scintigraphy as a method to examine renal function. To support the scintigraphy results, parallel histological and hematological examinations of unilateral ureter-obstructed rabbits were performed.

\section{Materials and Methods}

In vivo study. Ten 12-week-old male New Zealand white rabbits weighing $2.7-3.5 \mathrm{~kg}$ were randomly divided into two groups: salineinjected control group $(\mathrm{n}=5)$ and $99 \mathrm{~m}$ Tc-DMSA-injected group $(\mathrm{n}=5)$. Each rabbit was maintained in a seperate cage in an airconditioned room (temperature $20 \pm 2^{\circ} \mathrm{C}$, humidity $40 \sim 60 \%$ ) with illuminatation starting from 08:00 a.m. (temperature $20 \pm 2^{\circ} \mathrm{C}$ ). The purpose of this study was to assess non-invasive scintgeneral anesthesia before the proximal part of the right ureter was ligated with 2-0 silk at two places adjacent to the renal pelvis.

Scintigraphic evaluation. Scintigraphy was performed before surgical intervention, and at $0,1,2,3$, and 4 weeks after right ureter ligation. Data were obtained using a dual-head gamma camera with CT capacity (Infinia Hawkeye, GE Co., USA). Scintigraphy was performed at $2 \mathrm{~h}$ and $5 \mathrm{~h}$ after ear vein injection of $3 \mathrm{mCi}{ }^{99 \mathrm{mTc}-}$ DMSA or saline. Scintigraphic images were recorded every $2 \mathrm{sec}$ for $1 \mathrm{~min}$ and, after that, every $1 \mathrm{~min}$ for $25 \mathrm{~min}$. To calculate the percentage of relative renal function, regions of interest (ROIs) were drawn around each kidney on both anterior and posterior images of a $99 \mathrm{~m}$ Tc-DMSA static scan as well as around the background areas around each kidney (Figure 1A). 
Table I. Comparison of weight, width, height, and thickness of kidneys in rabbits with and without right ureter obstruction at 4 weeks after surgical intervention.

\begin{tabular}{lcccc}
\hline Ureter & $\begin{array}{c}\text { Weight } \\
(\mathrm{g})\end{array}$ & $\begin{array}{c}\text { Width } \\
(\mathrm{cm})\end{array}$ & $\begin{array}{c}\text { Height } \\
(\mathrm{cm})\end{array}$ & $\begin{array}{c}\text { Thickness } \\
(\mathrm{cm})\end{array}$ \\
\hline Normal & $10.88 \pm 0.40$ & $2.69 \pm 0.52$ & $3.50 \pm 0.88$ & $2.23 \pm 0.19$ \\
Obstructed & $17.91 \pm 0.79 *$ & $3.48 \pm 0.38$ & $4.44 \pm 1.16^{*}$ & $2.53 \pm 0.26$ \\
\hline
\end{tabular}

Values are presented as means \pm S.D. $(\mathrm{n}=5) .{ }^{*} p<0.05$.

Clincopathological evaluation. At intervals during the 4 weeks of scintigraphy and commencing on day 1 after surgical intervention, blood samples were taken to determine blood urea nitrogen (BUN) and creatinine levels. Serum was obtained following centrifugation at $1,008 \times g$ for $10 \mathrm{~min}$. At 4 weeks after ureter ligation, all rabbits were euthanized and the kidneys removed followed by overnight fixing in $10 \%$ buffered formalin. Subsequently, paraffin tissue sections were stained with hematoxylin and eosin using standard procedures.

Statistical analysis. Statistical analyses were performed using SPSS software (version 19.0.1.1; IBM SPSS Statistics for Windows; IBM Corp., Armonk, NY, USA). Data are presented as mean \pm standard deviation (S.D.) values. Normality and homogeneity of the data were confirmed before performing an analysis of variance (ANOVA). Differences among experimental groups were assessed by performing one-way ANOVA followed by Duncan's multiple range tests. Null hypotheses of no significant difference were rejected if the obtained $p$-values were less than 0.05 .

\section{Results}

${ }^{99 m}$ Tc-DMSA renal scintigraphy. The quantitative analysis included calculation of both kidney and background area. All kidneys were pea-shaped. The left kidney was observed to maintain a consistent size during the experimental periods, but the obstructed right kidney became progressively larger. Imaging results showed that the left kidney was approximately the same size each week, but the right kidney was different each week. The right kidney at 4 weeks postsurgical intervention exhibited hydronephrosis (Figure 1A).

Following ureter obstruction, uptake of ${ }^{99} \mathrm{~m}$ Tc-DMSA in the onstructed right kidney was less than that in the left kidney. Time-radioactivity curve analysis showed radiopharmaceutical uptake in both kidneys after bolus injection of ${ }^{99 \mathrm{~m}} \mathrm{Tc}-\mathrm{DMSA}$. An abnormal curve was observed in the obstructed right kidney, exhibiting a relatively small peak at about 2 min postinjection followed by prolonged, slowly decreasing level (Figure 1B). At 4 weeks after ureter obstruction, the obstructed right kidney had increased in size with its weight and hight significantly greater than those of the lefet kidney (Table I).

Clinicopathological results. BUN and serum creatinine levels were higher one week after performing right ureter
Table II. Temporal changes in blood urea nitrogen and serum creatinine levels in rabbits with right ureter obstruction.

\begin{tabular}{lccccc}
\hline Item & \multicolumn{5}{c}{ Weeks after obstruction } \\
\cline { 2 - 6 } & 0 & 1 & 2 & 3 & 4 \\
\hline $\begin{array}{l}\text { Blood } \\
\text { urea }\end{array}$ & $22.08 \pm 0.21$ & $32.93 \pm 1.47$ & $20.70 \pm 0.19$ & $23.18 \pm 0.07$ & $23.63 \pm 0.10$ \\
$\begin{array}{l}\text { nitrogen } \\
(\mathrm{mg} / \mathrm{ml})\end{array}$ & & & & & \\
$\begin{array}{l}\text { Serum } \\
\text { creatinine } \\
(\mathrm{mg} / \mathrm{ml})\end{array}$ & $1.29 \pm 0.25$ & $2.45 \pm 1.15$ & $1.47 \pm 0.24$ & $1.47 \pm 0.06$ & $1.47 \pm 0.15$ \\
\hline
\end{tabular}

Values are presented as means \pm S.D. $(n=5)$.

obstruction, but the increases were not significantly different form the before obstruction levels (Table II). Histopathological examination at 4 weeks post-obstruction showed tubular flattening and atrophy, enlargement of the interstitial region, extracellular matrix accumulation, and inflammatory cell infiltration. The tubulointestitial region of the ureter-obstructed right kidney appeared markedly degenerated, but no apparent structural changes were observed in the contralateral kidney (Figure 2).

\section{Discussion}

Urinary obstruction can result from a wide range of congenital, intraluminal, parietal, and extrinsic diseases that affect the urinary tract. In both the early stages and during follow-up of urinary obstruction, renal function should be assessed (9). Noninvasive means of determining the renal function level of individual kidneys would be advantageous during planning for surgical intervention or medical management of renal diseases. Several studies have shown a rapid decrease in glomerular filtration rate (GFR) in ureter-obstructed animals. RBF values in a dog model of ureter obstruction showed that RBF was transiently increased at 0-90 min post-obstruction and then gradually decreased (10). In the present study, GFR was reduced in the obstructed right kidney, but no change was observed in the contralateral left kidney. These results are consistent with the GFR results reported for rats and dogs with unilateral ureter obstructions $(11,12)$.

The ${ }^{99 \mathrm{~m}} \mathrm{Tc}-\mathrm{DMSA}$ is mainly bound to serum proteins (13) and enters proximal tubular cells either via glomerular filtration followed by re-absorption or by direct uptake from peritubular capillaries. The radionuclide ${ }^{99 \mathrm{~m}} \mathrm{Tc}$ emits gamma rays with an energy of $140 \mathrm{KeV}$ and has various diagnostic purposes. Radionuclide ${ }^{99} \mathrm{~m} \mathrm{Tc}$ has excellent physical properties for nuclear medicine imaging when used with a gamma camera, and is particularly useful for assessments using gamma camera with thin crystals that absorb more than 

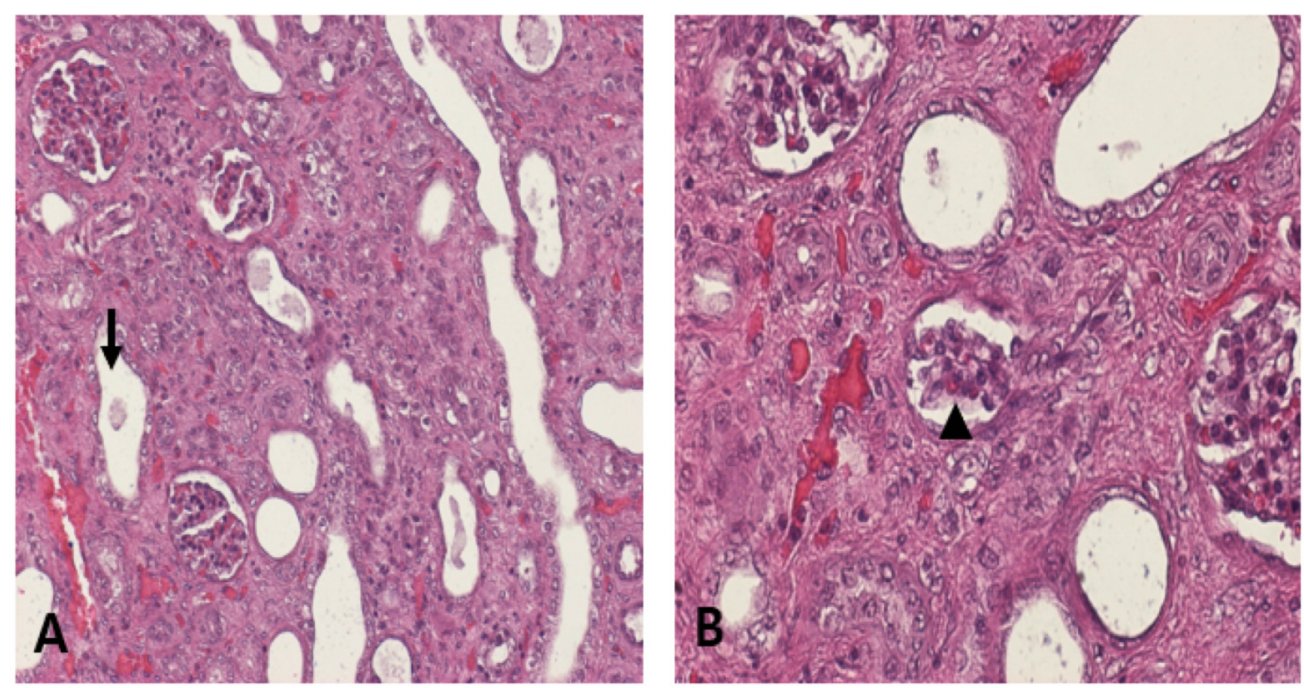

Figure 2. Microscopy image showing cell bodies in renal tubules (A, arrow) and glomerular condensation and pyknosis (B, arrow head). H\&E stain, magnification $\times 200$.

$90 \%$ of the radiation. Due to the half-life features of ${ }^{99 \mathrm{~m}} \mathrm{Tc}$, a low level of radioactivity can be injected, but a high-density image can be obtained. However, the quality of ${ }^{99 \mathrm{~m}} \mathrm{Tc}-\mathrm{DMSA}$ can be affected by many factors, including chemical purity and stability, manufacturing procedure, and radionuclide and radiochemical purity of the ${ }^{99 \mathrm{~m}} \mathrm{Tc}$-eluate (1).

Renal function can be accurately assessed by using ${ }^{99 \mathrm{~m}} \mathrm{Tc}-\mathrm{MAG} 3,{ }^{99 \mathrm{~m}} \mathrm{Tc}-\mathrm{DTPA}$, or ${ }^{99 \mathrm{~m}} \mathrm{Tc}-\mathrm{DMSA}$, and selection of appropriate agents can be based on biological properties, such as renal excretion mechanism and renal cell retention $(1,13)$, radioactive material and bound plasma-protein and plasma-clearance levels $(13,14)$. Among these agents, ${ }^{99 \mathrm{~m}} \mathrm{Tc}$-DMSA has been considered the most reliable method for measuring relative renal function (15), whereas, the most suitable tracer for renal cortex imaging remains under consideration (16). Previous studies have revealed that renal disease is affected by various factors, including age, time from diagnosis to initiation of bacterial therapy, urinary tract anomalies, recurrent infections, and the presence of bladder dysfunction (17). In our study, the right kidney showed hydronephrosis following right ureter ligation in rabbits. Hydronephrosis can result from several diseases, and conditions often associated with unilateral hydronephrosis include acute unilateral obstructive uropathy, ureter obstruction due to scars, tumors and uroliths, chronic unilateral obstructive uropathy, vesicoureteric reflux illness, and kidney stones. Unilateral hydronephrosis is revealed by imaging methods such as abdominal MR imaging, renal or abdominal CT scanning, venous pyelography, and renal or abdominal ultrasonography. However, these methods cannot evaluate the functioning level of individual kidneys.
Histopathological evaluation of renal parenchyma can be an objective method of predicting renal function. In our study, renal parenchyma showed a minimal degree of interstitial inflammation with mild dilation of the collecting tubules and Bowen's space. These results indicate that the renal functioning of the rabbits with an obstructed ureter was impaired. Urinary tract obstruction is usually caused by urolithiasis, metastatic cell carcinoma and tumors, enlarged lymph nodes, or external compression by peritoneal fibrosis (18). Bilateral urethral obstruction can lead to elevated serum creatinine levels (19), but unilateral urethral obstruction may result in normal serum creatinine levels if the contralateral kidney can excrete the daily amount of nitrogen waste (20). Our study showed that at one week after right ureter obstruction, BUN and creatinine levels were slightly higher than normal levels. However, these changes were not statistically significant. During the 4 weeks of the experiment, the left kidney continued to function normally.

In the present study, a time-radioactivity curve showed radiopharmaceutical radioactivity uptake after bolus injection of ${ }^{99} \mathrm{~m}$ Tc-DMSA. The radioactivity curve in the unobstructed left kidney exhibited a marked increase at approximately 2-4 min and then gradually declined. However, the radioactivity curve in the obstructed right kidney rose to a peak level at approximately $2 \mathrm{~min}$ and then maintained a similiar but slightly decreasing level for the reminder of the assessment period. Regardless, no significant difference in radiopharmaceutical uptakes of ${ }^{99 \mathrm{~m}} \mathrm{Tc}$-DMSA in the right and left kidneys was detected.

This study examined renal uptake of ${ }^{99 \mathrm{~m}} \mathrm{Tc}-\mathrm{DMSA}$ and analyzed hematological and histological results in individual 
kidneys in a rabbit model of right ureter obstruction. The results suggest that ${ }^{99 \mathrm{~m}} \mathrm{Tc}$-DMSA scintigraphy can be a sensitive, noninvasive method of renal function in unilaterally obstructed kidneys.

\section{Conflicts of Interest}

The Authors declare that they have no competing interests regarding this study.

\section{Authors' Contributions}

This study was designed by Jang and Choi BS. Jang and Choi SH analyzed the CT image and data collection. All Authors read and approved the final manuscript.

\section{Acknowledgements}

This research was supported by the Basic Science Research Program provided through the National Research Foundation of Korea and funded by the Ministry of Education (2018R1D1A1A09083556).

\section{References}

1 Lee WG, Kim JH, Kim JM, Shim KM, Kang SS, Chae HI and Choi SH: Renal uptakes of $99 \mathrm{mTc}_{\mathrm{T}} \mathrm{MAG}_{3},{ }^{99 \mathrm{mTc}-\mathrm{DTPA} \text {, and }}$ 99mTc-DMSA in rabbits with unilateral ureteral onstruction. In Vivo 24: 137-140, 2010. PMID: 20363984.

2 Miyazaki C, Harada H, Shuke N, Okizaki A, Miura M and Hirano T: 99mTc-DTPA dynamic SPECT and CT volumetry for measuring split renal function in live kidney donors. Ann Nucl Med 24: 189-195, 2010. PMID: 20213340. DOI: 10.1007/ s12149-010-0349-y

3 Summerlin AL, Lockhart ME, Strang AM, Kolettis PN, Fineberg NS and Smith JK: Determination of split renal function by 3D reconstruction of CT angiograms: a comparison with gamma camera renography. Am J Roentgenol 191: 1552-1558, 2008. PMID: 18941100. DOI: 10.2214/AJR.07.4023

4 Claudon M, Durand E, Grenier N, Prigent A, Balvay D, ChaumetRiffaud P, Chaumoitre K, Cuenod CA, Filipovic M, Galloy MA, Lemaitre L, Mandry D, Micard E, Pasquier C, Sebag GH, Soudant M, Vuissoz PA and Guillemin F: Chronic urinary obstruction: evaluation of dynamic contrast-enhanced MR urography for measurement of split renal function. Radiology 273: 801-812, 2014. PMID: 25102294. DOI: 10.1148/radiol.14131819

5 Li Q, Wu X, Qiu L, Zhang P, Zhang M and Yan F: Diffusionweighted MRI in the assessment of split renal function: comparison of navigator-triggered prospective acquisition correction and breath-hold acquisition. Am J Roentgenol 200: 113-119, 2013. PMID: 23255749. DOI: 10.2214/AJR.11.8052

6 Taylor A Jr and Lallone R: Differential renal function in unilateral renal injury: possible effects of radiopharmaceutical choice. J Nucl Med 26: 77-80, 1985. PMID: 2981302.

7 Russell CD, Thorstad BL, Stutzman ME, Yester MV, Fowler D and Dubovsky EV: The kidney; imaging with Tc-99m mercaptoacetyltriglycine, a technetium-labeled analog of iodohippurate. Radiology 172: 427-430, 1989. PMID: 2526350. DOI: $10.1148 /$ radiology.172.2.2526350
8 Wujanto R, Lawson RS, Prescott MC and Testa HJ: The importance of using anterior and posterior views in the calculation of differential renal function using $99 \mathrm{mTc}-\mathrm{DMSA}$. $\mathrm{Br}$ J Radiol 60: 869-872, 1987. DOI: 10.1259/0007-1285-60-717869

9 Jones RA, Grattan-Smith JD and Little S: Pediatric magnetic resonance urography. J Magn Reson Imaging 33: 510-526, 2011. PMID: 21563236. DOI: 10.1002/jmri.22474

10 Vaughan ED Jr, Marion D, Poppas DP and Felsen D: Pathophysiology of unilateral ureteral obstruction: studies from Charlottesville to New York. J Urol 172: 2563-2569, 2004. PMID: 15538209. DOI: 10.1097/01 ju.0000144286.53562.95

11 Yeh CH, Chiang HS, Lai TY and Chien CT: Unilateral ureteral obstruction evokes renal tubular apoptosis via the enhanced oxidative stress and endoplasmic reticulum stress in the rat. Neurourol Urodyn 30: 472-479, 2011. PMID: 21305585. DOI: 10.1002/nau.20855

12 Bhangdia DK, Gulmi FA, Chou SY, Mooppan UM and Kim H: Alterations of renal hemodynamics in unilateral ureteral obstruction mediated by activation of endothelin receptor subtypes. J Urol 170: 2057-2062, 2003. PMID: 14532853. DOI: 10.1097/01.ju.0000081956.16457.67

13 de Lange MJ, Piers DA, Kosterink JG, van Luijk WH, Meijer S, de Zeeuw D and van der Hem GK: Renal handling of technetium-99m DMSA: evidence for glomerular filtration and peritubular uptake. J Nucl Med 30: 1219-1223, 1989. PMID: 2544699.

14 Eshima D, Eshima L, Hansen L, Lipowska M, Marzilli LG and Taylor A Jr: Effect of protein binding on renal extraction of ${ }^{131} \mathrm{I}$ $\mathrm{OIH}$ and $99 \mathrm{mTc}-$ labeled tubular agents. J Nucl Med 41: $2077-$ 2082, 2000. PMID: 11138695.

15 Kawashima A, Sandler CM and Goldman SM: Current roles and controversies in the imaging evaluation of acute renal infection. World J Urol 16: 9-17, 1998. PMID: 9542009. DOI: 10.1007/ s003450050019

16 Piepsz A, Blaufox MD, Gordon I, Granerus G, Majd M, O'Reilly P, Rosenberg AR, Rossleigh MA and Sixt R: Consensus on renal cortical scintigraphy in children with urinary tract infection. Scientific committee of radionuclides in nephrourology. Semin Nucl Med 29: 160-174, 1999. PMID: 10321827. DOI: 10.1016/s0001-2998(99)80006-3

17 Ditchfield MR, de Campo JF, Nolan TM, Cook DJ, Grimwood K, Powell HR, Sloane R and Cahill S: Risk factors in the development of early renal cortical defects in children with urinary tract infection. Am J Roentgenol 162: 1393-1397, 1994. PMID: 8192006. DOI: 10.2214/ajr.162.6.8192006

18 Klahr S: Urinary tract obstruction. Semin Nephrol 21: 133-45, 2001. PMID: 11245776. DOI: 10.1053/snep.2001.20942

19 Meola M, Samoni S, Petrucci I and Ronco C: Clinical scenarios in acute kidney injury: post-renal acute kidney injury. Contrib Nephrol 188: 64-68, 2016. PMID: 27170168. DOI: 10.1159/ 000445468

20 Gosmanova EO, Baumgarten DA and O'Neill WC: Acute kidney injury in a patient with unilateral ureteral obstruction. Am J Kidney Dis 54: 775-779, 2009. PMID: 19592146. DOI: 10.1053/j.ajkd.2009.03.028

Received June 9, 2020

Revised June 30, 2020

Accepted July 1, 2020 